\title{
ASPECTOS TEÓRICOS DOS MÉTODOS DIRETO E INDIRETO DE VALORAÇÃO ECONÔMICA DO MEIO AMBIENTE
}

\author{
Fernanda Dassie Rangel ${ }^{1}$ \\ Bruno Fardim Christo ${ }^{2}$ \\ Winny Silva Trugilho ${ }^{3}$ \\ Gabriel Mancini Antunes da Silva ${ }^{4}$ \\ Elaine Cristina Gomes da Silva ${ }^{5}$
}

Resumo: A valoração ambiental tem sido um assunto muito discutido por muitos estudiosos atualmente. $O$ objetivo deste trabalho é apresentar e discutir sucintamente os métodos diretos e indiretos de valoração econômica do meio ambiente por meio de revisão de literatura. Para tal, buscou-se informações acerca do conteúdo, construindo assim uma pesquisa exploratória, descritiva e qualitativa. Ao final pôde-se perceber que as opiniões das pessoas e o valor atual de mercado contribuem consideravelmente no processo de valoração e que utilizam direta ou indiretamente um recurso ambiental.

Palavras-chave: Valoração ambiental; Economia ambiental; Meio ambiente.

\footnotetext{
${ }^{1}$ Engenharia Química/UFES, Brasil. E-mail: fernanda.dassierangel@gmail.com.

2 Agronomia/UFES, Brasil. E-mail: brunochristo@hotmail.com.

${ }^{3}$ Zootecnia/UFES, Brasil. E-mail: winnytrugilho@hotmail.com.

4 Engenharia Florestal/UFES, Brasil. E-mail: twilight.mancini@hotmail.com.

${ }^{5}$ Administração/UNESC, Brasil. E-mail: ecristinags@gmail.com.
} 